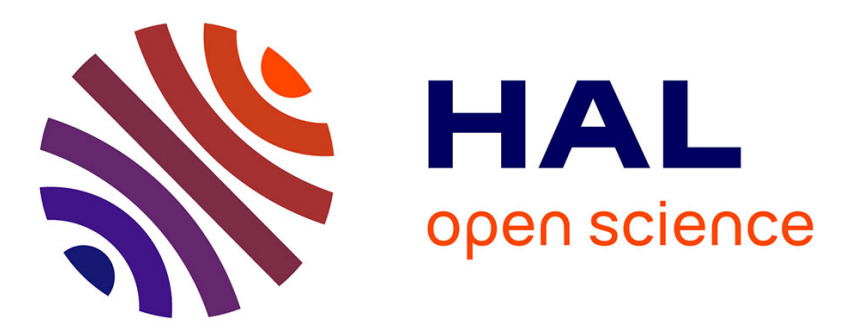

\title{
Watching Support System by Annotation Displaying According to Fighting Game Situations
}

\author{
Tomoki Kajinami, Kazuya Hasegawa
}

\section{To cite this version:}

Tomoki Kajinami, Kazuya Hasegawa. Watching Support System by Annotation Displaying According to Fighting Game Situations. 16th International Conference on Entertainment Computing (ICEC), Sep 2017, Tsukuba City, Japan. pp.435-438, 10.1007/978-3-319-66715-7_57 . hal-01771282

\section{HAL Id: hal-01771282 \\ https://hal.inria.fr/hal-01771282}

Submitted on 19 Apr 2018

HAL is a multi-disciplinary open access archive for the deposit and dissemination of scientific research documents, whether they are published or not. The documents may come from teaching and research institutions in France or abroad, or from public or private research centers.
L'archive ouverte pluridisciplinaire HAL, est destinée au dépôt et à la diffusion de documents scientifiques de niveau recherche, publiés ou non, émanant des établissements d'enseignement et de recherche français ou étrangers, des laboratoires publics ou privés. 


\title{
Watching Support System by Annotation Displaying According to Fighting Game Situations
}

\author{
Tomoki Kajinami $^{1 *}$ and Kazuya Hasegawa ${ }^{1}$ \\ ${ }^{1}$ Okayama University of Science, 1-1 Ridai-cho, Okayama City, Japan \\ kajinami@mis.ous.ac.jp
}

\begin{abstract}
This study proposes a watching support system for a beginner watcher of fighting games. The fighting games is a type of e-Sports genre similar to Karate and boxing. Two game characters (e.g., a grappler) fight each other in the game. As with actual fighting sports, positioning on the game field of the game character in this game is important in winning the match. A concept of displaying annotation according to situations based on the characters' positioning for a beginner watcher of the fighting games is proposed from a previous study. The present paper defines three typical situations and proposes keyword and graphic annotations to encourage understanding of the match and emphasize amusement for the beginner watcher of fighting games. This study also develops a prototype system, and their annotations are superimposed on the match video. As a result, the proposed system can support beginner watchers through subjective experiments.
\end{abstract}

Keywords: e-Sports · Fighting Game · Watcher Support

\section{Introduction}

This study proposes a watching support system for a beginner watcher of fighting games, a type of e-Sports genre similar to Karate and boxing. Two game characters (e.g., a grappler) fight each other in the game. A vast amount of e-Sports competitions have recently been held worldwide [1]. Accordingly, the analysis of the competitive game players' community has been studied [3]. As with actual fighting sports, the players must consider the positioning of the game characters on the game field to win a fighting game match. A concept of displaying annotation according to situations based on the characters' positioning for a beginner watcher of the fighting games is proposed herein from a previous study [2]. The present paper defines three typical situations, namely long-distance, short-distance, and corner situations, and proposes keyword and graphic annotations to encourage understanding of the point of the match and emphasize amusement for a beginner watcher of the fighting games. The game characters' positions are extracted from the match video by template matching. Furthermore, this study develops a prototype system, and their annotations are superimposed on the match video. This study shows that the proposed system can support beginner watchers through subjective experiments. 


\section{Displaying Annotation According to Three Typical Situations}

Long-distance, short-distance, and corner situations are defined herein. The game screen width is assumed to be 1280 pixels. The $x$ coordinate of the game character on the left is $x_{l}$, while that on the right is $x_{r}$. Figure 1(a) shows the long-distance situation defined by $x_{r}-x_{l} \geqq 300$ pixels. Figure 1(b) presents the short-distance situation defined by $x_{r}-x_{l}<300$ pixels. Meanwhile, Figure 1(c) illustrates the corner situation defined by $\left(x_{l}<200 \wedge 200 \leqq x_{r} \leqq 1080\right) \vee\left(200 \leqq x_{l} \leqq 1080 \wedge 1080<x_{r}\right)$.

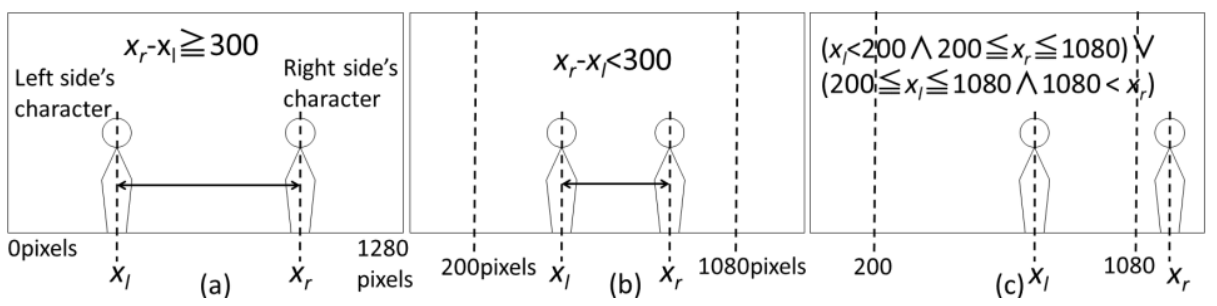

Fig. 1. Three typical situations in fighting games.

In this study, keyword and graphic annotations are proposed depending on the three typical situations. Table 1 summarizes the correspondence relationship between their situations and displayed annotations. The keyword annotations vividly show the contents of situations. The graphic annotations indicate the places, where a high possibility of a battle occurrence on the screen exists. The game players in the long-distance situation tend to wait and see the play of the opponent, and too much intense battle is not done. "Wait and see" is displayed, and a large blue rectangle is displayed between the characters. Meanwhile, the game players in the short-distance situation tend to actively attack opponents. Intense battle is done, and the victory or defeat tends to be decided at a stretch. "! Explosive !" is displayed, and a small rectangle is displayed around the characters. In the corner situation, the other character is advantageous, while the other chasing a corner is not. The character on the advantage side tends to move to close off the escape path of the disadvantage-side character. An important battle in the game tends to be done in the sky space rather than in front of both characters. "Chance" and "!" are displayed according to the advantage or disadvantage side. A rectangle is displayed in the sky between the two characters. Section 3 presents the displaying examples of the annotations.

Table 1. Displaying annotations according to the three situations.

\begin{tabular}{|l|l|l|}
\hline Situations & Keyword annotation & Graphic annotation \\
\hline Long-distance & Wait and see & Large blue rectangle \\
\hline Short-distance & ! Explosive ! & Small green rectangle \\
\hline Corner & $\begin{array}{l}\text { Chance (Advantage side) } \\
!(\text { Disadvantage side) }\end{array}$ & Red rectangle \\
\hline
\end{tabular}




\section{Prototype System}

The character positions herein are extracted from a game movie by template matching using OpenCV. The template image is an image of a part of the character image of 40 $\times 40$ pixels. The prototype system is developed for a specific game title "Street Fighter V."

Figure 2 shows an execution example of the proposed system. Figure 2(a) presents an example, in which an annotation is displayed in the long-distance situation. "Wait and see" is displayed, and a blue rectangle is shown to cover a large area between the two characters. Figure 2(b) depicts an example, in which the annotation is presented in the short-distance situation. "Explosive" and a green rectangle are displayed around both characters. Figure 2(c) shows an example, in which the annotation is presented in the corner situation. "Chance" is displayed around the advantage-side character, while "?" is displayed around the disadvantage side character. A red rectangle is displayed on the sky between the two characters.

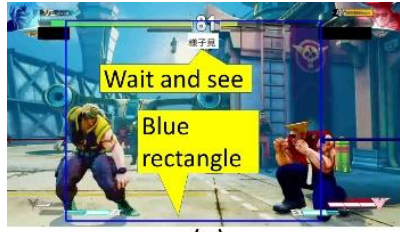

(a)

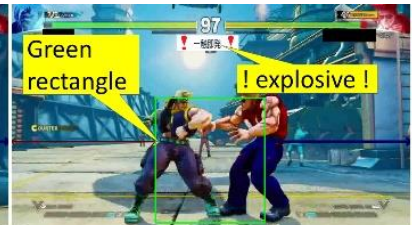

(b)

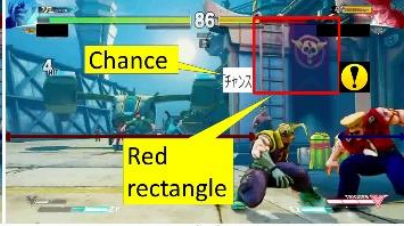

(c)

Fig. 2. Execution example of the prototype system.

\section{Experiment}

The experiment aimed to evaluate whether the point of the match becomes easy to understand and emphasize amusement by the proposed system. We prepared the match videos with annotations using the proposed system and without annotations. The subjects were beginner watchers, who were not competitive players. Each subject watched the match videos with proposed annotations and without annotations. The order of video watching was different for each subject. A total of 10 subjects (A-J) participated in the experiment.

Table 2. Evaluation scores by the subjects.

\begin{tabular}{|l|l|l|l|l|l|l|l|l|l|l|c|}
\hline & A & B & C & D & E & F & G & H & I & J & Average \\
\hline Video with annotations & 7 & 3 & 5 & 5 & 4 & 7 & 3 & 7 & 7 & 6 & 5.4 \\
\hline Video without annotations & 3 & 5 & 2 & 4 & 3 & 3 & 3 & 3 & 6 & 4 & 3.6 \\
\hline
\end{tabular}

Table 2 summarizes the experimental result on the amusement by easiness of point of the match (7: Good, 1: Bad). We asked the subjects to evaluate whether the point of the match became easy to understand with the proposed annotation. Table 2 shows that the average evaluation value was higher in the proposed system. Eight out of 10 subjects highly evaluated the proposed annotations. In other words, there is a tendency that 
the proposed annotations can emphasize amusement by the easiness of the match highlight. We then focused on the comments obtained by the subjects, and performed a qualitative evaluation of the proposed system.

The typical positive comments obtained by the subjects were as follows. "I could get prediction of the battle (I could understand the point of the battle). (A and I);" "It is interesting by displayed annotations. (E, F, and G);" "Even in an unknown game, I could know where to focus on. (H);" and "It become easy to follow changing in battle. (J)." These comments, especially those from subject $\mathrm{H}$, implied that the point of the match became easy to understand with the proposed system. The proposed system can support a beginner watcher with poor prior knowledge of the game title.

The typical negative comments obtained by the subjects were as follows. "The screen was complicated, and the screen was sometimes difficult to see. (D, E, G, and J)" and "When the keyword and graphic annotations are viewed at the same time, the game characters are difficult to see. (F and G)." These comments expressed the need for improvements in visibility as the future works. Moreover, subject B said "I can note point of battle when without annotations," and obtained a low score for the proposed system. He was a beginner of the fighting game, but had experience of a similar action game. Therefore, his watching level can be considered higher than that of the other beginner watchers. His comment imposed a consideration of the annotation displaying methods according to the watchers' watching levels as a future work.

\section{Conclusion}

This study proposed a watching support system for a fighting game's beginner watchers. Three typical situations were defined herein based on the game characters' positions in the game field. The proposed system displayed keyword and graphic annotations depending on the situations to support understanding of the watching point of the match. The effectiveness of the proposed system was examined through subjective experiments. The result showed that the proposed system can support understanding of the point of battle and emphasize amusement as regards watching the fighting game matches. The future work will focus on improving visibility and examining the annotation presentation methods according to the watchers' watching levels.

\section{References}

1. Adamus, T.: Playing Computer Games as Electronic Sport: In Search of a Theoretical Framework for New Research Field. In: Fromme, J. and Unger, A. (eds.), Computer Games and New Media Cultures: A Handbook of Digital Game Studies, pp. 477-490. Springer (2012).

2. Kajinami, T.: Supporting Method for Watching e-Sports Considering Relationship between Player's Conception and Game Field. In: Replaying Japan Again: 2nd International Japan Game Studies Conference 2014, pp. 50-51 (2014).

3. Taylor, T. L.: Raising the Stakes: E-sports and the Professionalization of Computer Games. The MIT Press (2012). 